\title{
Outcome of Posterior-Only Approach for Severe Rigid Scoliosis: A Retrospective Report
}

\author{
BABAK MIRZASHAHI, MD, ${ }^{1}$ MERSAD MOOSAVI, MD ${ }^{2}$ MOHSEN ROSTAMI, MD, PHD ${ }^{3,4}$ \\ ${ }^{I}$ Department of Orthopedic Surgery, Joint Reconstruction Research Center, Tehran University of Medical Sciences, Tehran, Iran, ${ }^{2}$ Department of Orthopedic \\ Surgery, Tehran University of Medical Sciences, Tehran, Iran, ${ }^{3}$ Sports Medicine Research Center, Neuroscience Institute, Tehran University of Medical Sciences, \\ Tehran, Iran, ${ }^{4}$ Department of Neurosurgery, Shariati hospital, Tehran University of Medical Sciences, Tehran, Iran
}

\begin{abstract}
Background: The management of severe scoliosis may lead to significant complications, and adequate mobilization is a key step to achieve maximal correction, usually requiring extensive approaches. There is still no consensus on the management of these severe and rigid curves. In this study we evaluated the clinical and radiologic outcome of a posterior-only approach with multilevel asymmetric Ponte osteotomy with a minimum of 2 years' followup.

Methods: In this retrospective study, 23 patients with severe and rigid adolescent idiopathic scoliosis who underwent surgery with a single-staged posterior-only approach were included. The surgical procedures in these patients were excision of posterior ligaments and spinous process, partial laminectomy in caudal part of lamina, excision of the ligamentum flavum, facetectomies, and multilevel asymmetric posterior column osteotomies (Ponte) followed by instrumented fusion. Clinical records - including demographic data; operating time; hospitalization time; blood loss; number of segments instrumented, fused, and osteotomized; functional improvement; follow-up duration; and complications-were recorded.

Results: The mean preoperative Cobb angle of major curve in coronal plan was $97.5^{\circ}$ (range, $82^{\circ}-131^{\circ}$ ) with the mean flexibility of $21.4^{\circ}$ (range, $10^{\circ}-25^{\circ}$ ) on bending radiography. The mean immediate postoperative Cobb angle of major curve was $34.8^{\circ}$ (range, $17^{\circ}-61^{\circ}$ ), showing a $64.2 \%$ correction. The mean preoperative coronal and sagittal imbalances of 3.8 and $4.2 \mathrm{~cm}$ were improved to 1.0 and $1.3 \mathrm{~cm}$ at postoperative measurements, respectively. A mean of 6.1 (range, 5-9) vertebral segments were osteotomized. We experienced no major complications.

Conclusions: We found that a posterior-only procedure in patients with severe and rigid adolescent idiopathic scoliosis could provide correction rate, coronal and sagittal balance, and clinical outcomes comparable with other procedures. Using this technique can eliminate the need for the anterior release, with the associated complications related to anterior surgery, in the treatment of severe rigid scoliosis.
\end{abstract}

Other \& Special Categories

Keywords: adolescent idiopathic scoliosis, severe and rigid, posterior-only approach

\section{INTRODUCTION}

Scoliosis is a 3-dimensional spinal deformity with coronal, sagittal curvature and axial rotation of the vertebral bodies. ${ }^{1}$ Adolescent idiopathic scoliosis (AIS) is considered to be the most common type of idiopathic scoliosis. Untreated or improper management of idiopathic scoliosis may lead to severe complications related to curve progression. Delay in diagnosis and treatment, especially in aggressive patterns, may lead to severe and rigid idiopathic curves. Severe rigid idiopathic scoliosis has $<25 \%$ of correction on bending films and major curve higher than $80 .^{2}$

Accurate and early management of AIS can effectively control progression by establishing a balanced, stable spine with solid arthrodesis. Severe and rigid scoliosis is uncommon in developed countries where patients have ready access to evaluation and treatment. However, it is common in undeveloped countries because of the lack of medical insurance and public education about health care, which results in delayed referral to spine specialists. $^{3}$ In developing countries, about $30 \%$ of patients with scoliosis present late with severe rigid scoliosis, and the ideal waiting time for scoliosis surgery may reach more than 5 years. ${ }^{4}$

The management of scoliotic patients with severe curves may lead to significant complications related to extended exposure and blood loss, cord injury, and pulmonary compromise. The goal of an operative treatment is to do an effective correction 
of the coronal, sagittal, and rotational deformities to improve the patient's quality of life and cardiopulmonary status, and to prevent painful degeneration and curve progression. ${ }^{5}$ In rigid and severe curves adequate mobilization is a key step to achieve maximal correction, usually requiring extensive approaches. Halo traction, internal temporary distraction, anterior releases, osteotomies, and apical vertebral resection are often used in combination to achieve optimal results. Satisfactory results have been reported in the treatment of severe rigid adolescent idiopathic scoliosis by combined anterior release and posterior instrumented fusion. Anterior discectomies and corpectomies, and posterior facetectomies, laminectomies, and ligament releases are done, and the spine is then instrumented and fused. Because of cardiopulmonary limitations in patients with severe curves, anterior procedures may aggravate cardiopulmonary function and are not ideal in these patients. ${ }^{6}$ Some other complications, like adjacent-organ injuries, may occur in anterior procedures. In recent years, with the advancement of thoracic pedicle screw fixation, a single posterior-only procedure has been popularized in the treatment of severe AIS., ${ }^{7,8}$ Segmental pedicle screw fixation distributes the stress on multiple levels and provides spine surgeons with more powerful correction forces. ${ }^{8,9}$ In addition, vertebral column resection (VCR) is a technique designed for rigid severe kyphoscoliosis deformities. ${ }^{2,10,11}$ Translation of spinal column and controlled manipulation of both the anterior and posterior column with active reconstruction are advantages of this technique.

There is still no consensus in the management of these severe and rigid curves. The purpose of this study was to report the clinical and radiologic outcome of posterior-only approach with multilevel asymmetric Ponte osteotomy on patients with severe rigid scoliosis with a minimum of 2 years' follow-up.

\section{MATERIALS AND METHODS}

In this retrospective study, 23 patients with severe and rigid adolescent idiopathic scoliosis underwent surgery between 2012 and 2016 in the orthopedic department of Imam Complex Hospital in Tehran by a single spine surgeon (B.M.). Consent for data collection was obtained from all patients and/or their guardians. The study was approved by the Institutional Review Board at our hospital.
Using the Lenke classification system, the patients were grouped into 6 different types. ${ }^{12}$ Inclusion criteria were: (1) diagnosis of adolescent idiopathic scoliosis, (2) age between 11 and 20 years at the time of surgery, (3) rigid severe scoliosis (defined as Cobb angle more than $80^{\circ}$ and flexibility index of less than $25 \%$ ), and (4) no previous surgery and no preoperative treatment, such as halotraction. Exclusion criteria were as follows: (1) patients who received a diagnosis of other kinds of scoliosis, such as neuromuscular scoliosis and congenital scoliosis; (2) juvenile or adult patients; or (3) patients with severe pulmonary, cardiovascular, neurologic, and other comorbidities.

All patients underwent single-staged posterior approach surgery with pedicle screw construct without any anterior approach. Additionally, multilevel asymmetric posterior vertebral osteotomy was used for the correction of severe and rigid curves.

Clinical records, including demographic data, operating time, hospitalization time, blood loss, number of segments instrumented and osteotomized, functional improvement, follow-up duration, and complications, were reviewed. The operation time was recorded from the start of incision to the end of wound closure. The intraoperative blood loss was calculated by the sum of the volume of suction and increased pad weight $(1 \mathrm{~g}=1 \mathrm{~mL})$. Type of scoliosis according to Lenke classification was identified, and measurements of curve magnitude, flexibility of curve, and sagittal and coronal balance were made on preoperative standing anteroposterior, lateral, and bending radiographs. Apical vertebral translation for thoracic curves was defined as the distance between the $\mathrm{C} 7$ plumb line and the center of the apical vertebral body, and for thoracolumbar and lumbar curves was based on the distance between the central sacral vertical line and the center of the apical vertebral body or disc. The coronal curve was measured using the Cobb method. Coronal balance was measured on the basis of the distance between the C7 plumb line and the center sacral line. Sagittal balance was measured based on distance between C7 plumb line and posterosuperior aspect of S1. For both coronal and sagittal measurements, balance was considered abnormal if the distance was greater than $2 \mathrm{~cm}$. Measurement of vertebral rotation was done using the Nash-Moe method. Thoracic kyphosis was 

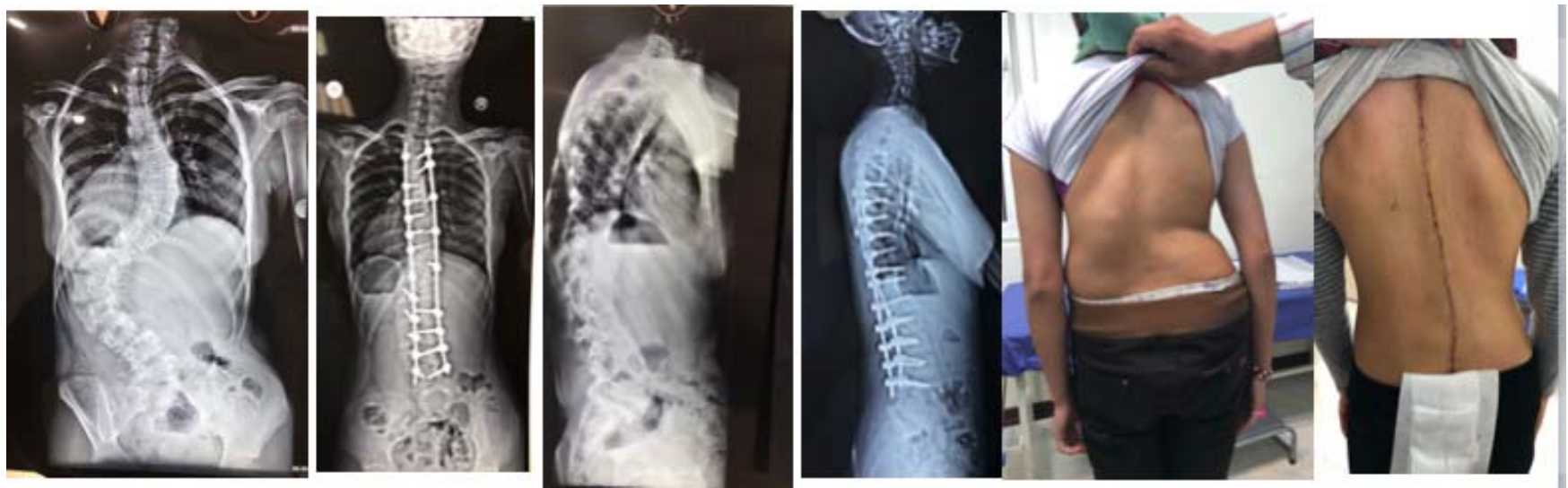

Figure. The preoperative and postoperative findings of one of our patients with severe rigid scoliosis.

measured using the Cobb method from the superior end plate of T5 to the inferior end plate of T12.

Magnetic resonance imaging of the spine, including cervical, thoracic, and lumbosacral segments, was performed preoperatively to exclude congenital intramedullary anomalies. Preoperative pulmonary function test was also performed for all patients. Wake-up test was performed in all patients without intraoperative neurophysiologic monitoring and spine navigation aids. Fluoroscopy was used to assess the screws' position. All patients ambulated during the first week postoperatively and were protected by a custom-made thoracolumbosacral orthosis for 3 to 6 months.

\section{Surgical Technique}

All patients had a single-staged posterior-only approach performed by the senior author, which included an anatomic exposure of posterior bony structure with a subperiosteal dissection to reduce hemorrhage and curve's stiffness. Then, insertion of bilateral pedicle screws based on preoperative surgical planning was done and excision of posterior ligaments and spinous processes at the levels that were candidates for an asymmetric Ponte osteotomy was completed. Partial laminectomy in the caudal and cephalad parts of lamina, excision of the ligamentum flavum, complete facetectomies, and multilevel asymmetric posterior column osteotomies (Ponte) were done, respectively. In contrast to standard Ponte osteotomy, in asymmetrical Ponte, the resected bony structure of convex side was wider than the concave side, creating nonparallel gaps. The osteotomy started from the apex of the curve and its upper and lower segments. Based on magnitude and flexibility of curve, especially mobility, observed during surgery among other segments of the main curve, more segment osteotomies could be perform. Bilateral precontoured rods were inserted, and by compression maneuver via segmental instrumentation the residual gaps were closed. The correction technique was a combination of derotation, translation, compression, and distraction. Arthrodesis was carried out using local autologous bone graft after meticulous decortication of posterior element. Mean arterial blood pressure was maintained at 65 to $80 \mathrm{mmHg}$ during the surgery. Cefazolin was used for preoperative antibiotic prophylaxis and administered 30 to 60 minutes before the skin incision and continued for 24 to 48 hours after surgery. All of the patients received tranexamic acid perioperatively. ${ }^{13}$ To maintain core body temperature and reduce the likelihood of coagulopathy, postoperative warming blankets and warmed intravenous fluids were used. Subfascial drain was kept for 48 to 72 hours after surgery. Patients mobilized during the first week after surgery and custom-made plastic orthosis was, worn for 3 to 6 months during activity (Figure).

\section{Statistical Analysis}

Patients' preoperative ages, Cobb angles, and coronal and sagittal balance before and after surgery and at last follow-up, as well as intraoperative blood losses, transfusions, operation and hospitalization times, fusion segments, and complications, were all recorded, and descriptive analysis of the data was done using SPSS 16 (SPSS Inc, Chicago, IL). 
Mirzashahi et al.

Table 1. Descriptive findings of patients with severe rigid scoliosis who underwent posterior-only corrective surgery.

\begin{tabular}{|c|c|c|c|c|c|c|c|}
\hline $\begin{array}{l}\text { Case } \\
\text { Number }\end{array}$ & $\begin{array}{l}\text { Age, } \\
\text { y/Sex }\end{array}$ & $\begin{array}{c}\text { Follow-Up, } \\
\text { mo }\end{array}$ & $\begin{array}{l}\text { Lenke } \\
\text { Type }\end{array}$ & $\begin{array}{l}\text { Preoperative } \\
\text { Cobb Angle }\end{array}$ & $\begin{array}{c}\text { Fixation } \\
\text { Extent }\end{array}$ & $\begin{array}{c}\text { No. of Osteotomized } \\
\text { Segments }\end{array}$ & $\begin{array}{c}\text { Postoperative } \\
\text { Cobb Angle }\end{array}$ \\
\hline 1 & $16 / \mathrm{M}$ & 31 & 1 & 82 & T3-L2 & 5 & 23 \\
\hline 2 & $18 / \mathrm{F}$ & 46 & 3 & 112 & T3-L5 & 6 & 47 \\
\hline 3 & $15 / \mathrm{F}$ & 28 & 1 & 84 & T4-L3 & 5 & 31 \\
\hline 4 & $17 / \mathrm{F}$ & 44 & 1 & 85 & T3-L3 & 5 & 29 \\
\hline 5 & $14 / \mathrm{M}$ & 52 & 5 & 83 & T8-L5 & 5 & 17 \\
\hline 6 & $19 / \mathrm{F}$ & 37 & 3 & 94 & T3-L4 & 6 & 26 \\
\hline 7 & $13 / \mathrm{M}$ & 29 & 6 & 111 & T3-S1 & 7 & 51 \\
\hline 8 & $16 / \mathrm{F}$ & 41 & 4 & 115 & T2-L5 & 7 & 61 \\
\hline 9 & $19 / \mathrm{F}$ & 38 & 2 & 82 & T2-L3 & 6 & 33 \\
\hline 10 & $15 / \mathrm{M}$ & 34 & 1 & 85 & T3-L2 & 5 & 21 \\
\hline 11 & $20 / \mathrm{F}$ & 45 & 3 & 87 & T3-L4 & 6 & 32 \\
\hline 12 & $16 / \mathrm{M}$ & 30 & 6 & 103 & T3-L5 & 7 & 48 \\
\hline 13 & $15 / \mathrm{F}$ & 27 & 1 & 81 & T4-L2 & 5 & 19 \\
\hline 14 & $18 / \mathrm{F}$ & 51 & 3 & 106 & T3-L5 & 7 & 32 \\
\hline 15 & $17 / \mathrm{F}$ & 43 & 4 & 131 & $\mathrm{~T} 2-\mathrm{L} 5$ & 9 & 57 \\
\hline 16 & $13 / \mathrm{M}$ & 36 & 1 & 92 & T2-L2 & 6 & 30 \\
\hline 17 & $14 / \mathrm{F}$ & 40 & 6 & 125 & $\mathrm{~T} 4-\mathrm{S} 1$ & 8 & 41 \\
\hline 18 & $17 / \mathrm{F}$ & 32 & 3 & 91 & T4-L4 & 6 & 36 \\
\hline 19 & $16 / \mathrm{M}$ & 32 & 1 & 87 & T3-L3 & 5 & 31 \\
\hline 20 & $18 / \mathrm{F}$ & 30 & 3 & 110 & $\mathrm{~T} 2-\mathrm{L} 5$ & 7 & 44 \\
\hline 21 & $14 / \mathrm{F}$ & 26 & 1 & 91 & $\mathrm{~T} 2-\mathrm{L} 3$ & 6 & 28 \\
\hline 22 & $17 / \mathrm{M}$ & 42 & 3 & 110 & T3-L5 & 7 & 42 \\
\hline 23 & $16 / \mathrm{F}$ & 37 & 1 & 96 & T3-L3 & 6 & 22 \\
\hline
\end{tabular}

\section{RESULTS}

There were 8 males and 15 females (23 patients), with an average age of 16.2 years (range, 13-20 years). Based on Lenke classification of AIS, patients classified as: 9 type 1 (single thoracic curve), 1 type 2 (double thoracic curves), 7 type 3 (double major curves), 2 type 4 (triple major curves), 1 type 5 (lumbar/thoracolumbar), 3 type 6 (lumbar/ thoracolumbar-main thoracic).

As shown in Table 1, the preoperative Cobb angle of major curve in the coronal plan was $97.5^{\circ}$ (range, $82^{\circ}-131^{\circ}$ ), with flexibility of $21.4 \%$ (range, $10 \%-$ $25 \%$ ) on bending radiography and corrected to $34.8^{\circ}$ (range, $17^{\circ}-61^{\circ}$ ) at immediate postoperative measurement, showing a $64.2 \%$ scoliosis correction. At the most recent follow-up, the major curve showed a $62 \%$ scoliosis correction compared with the preoperative curve measurement, and only a $2 \%$ loss of correction compared with the immediate postoperative curve measurement. The mean preoperative coronal and sagittal imbalances of 3.8 and $4.2 \mathrm{~cm}$ were improved to 1.0 and $1.3 \mathrm{~cm}$ at postoperative measurements, respectively. The preoperative apical vertebral translation of the major curve was $8.9 \mathrm{~cm}$ (range, 4.1-12.0 cm), which decreased to $3.1 \mathrm{~cm}$ (range, 1.2-6.1 cm). The preoperative apical vertebral translation of the minor curve was $2.1 \mathrm{~cm}$ (range, $0.3-4.5 \mathrm{~cm}$ ) and improved to $1.2 \mathrm{~cm}$ (range, $02-2.8 \mathrm{~cm}$ ) postoperatively. The average preoperative thoracic kyphosis of $25^{\circ}$ (range, $8^{\circ}-52^{\circ}$ ) was decreased to $21^{\circ}$ (range, $\left.10^{\circ}-33^{\circ}\right)$.

The mean instrumented fusion segment was 13.1 segments (range, 10-16 segments). The average number of pedicle screws used was 20.7 (range, 16-24), and a mean of 6.1 (range, 5-9) vertebral segments were osteotomized. The mean operation time and blood loss were 246.7 minutes (range, 180 300 minutes) and $660 \mathrm{~mL}$ (range, 350-1200 mL), respectively. A total of 5 patients $(21.7 \%)$ received a red blood cell transfusion during admission. The median hospital stay was 4.2 days (range, 2-10 days).

We experienced no major complications (instrumentation loosening, infection, or neurologic or visceral impairment). Pseudoarthrosis was not seen in any case during follow-up period, although minor complications, such as ileus, atelectasis, transient urinary retention, and syndrome of inappropriate antidiuretic hormone, were observed in some cases (Table 2).

\section{DISCUSSION}

In our study, we treated the large and rigid idiopathic scoliosis curves (Cobb angle of $>80^{\circ}$ with a rigid flexibility of $<25 \%$ ) with the posterior segmental instrumentation and posterior element osteotomy, and the results were satisfactory. In our study average blood loss, surgery time, and hospital 
Table 2. Intraoperative and postoperative complications of patients.

\begin{tabular}{|c|c|c|c|c|c|}
\hline $\begin{array}{l}\text { Case } \\
\text { Number }\end{array}$ & $\begin{array}{c}\text { Intraoperative } \\
\text { Blood Loss, } \\
\text { mL }\end{array}$ & $\begin{array}{l}\text { Operation } \\
\text { Time, min }\end{array}$ & $\begin{array}{c}\text { Hospital } \\
\text { Stay, } \\
\text { Days }\end{array}$ & $\begin{array}{l}\text { ICU, } \\
\text { Days }\end{array}$ & $\begin{array}{l}\text { Postoperative } \\
\text { Complications }\end{array}$ \\
\hline 1 & 430 & 210 & 3 & 1 & - \\
\hline 2 & 840 & 280 & 5 & 2 & - \\
\hline 3 & 520 & 180 & 3 & 1 & - \\
\hline 4 & 450 & 205 & 3 & 1 & - \\
\hline 5 & 600 & 190 & 4 & 1 & - \\
\hline 6 & 590 & 260 & 4 & 1 & $\begin{array}{l}\text { Transient urinary } \\
\text { retention }\end{array}$ \\
\hline 7 & 790 & 290 & 5 & 2 & - \\
\hline 8 & 810 & 290 & 5 & 2 & SIADH \\
\hline 9 & 460 & 240 & 3 & 1 & - \\
\hline 10 & 520 & 200 & 3 & 1 & - \\
\hline 11 & 620 & 250 & 4 & 1 & - \\
\hline 12 & 710 & 270 & 5 & 1 & Atelectasis \\
\hline 13 & 570 & 210 & 3 & 1 & - \\
\hline 14 & 730 & 270 & 5 & 1 & - \\
\hline 15 & 890 & 300 & 6 & 2 & - \\
\hline 16 & 680 & 230 & 4 & 1 & - \\
\hline 17 & 870 & 300 & 6 & 2 & SIADH \\
\hline 18 & 580 & 250 & 4 & 1 & - \\
\hline 19 & 670 & 220 & 3 & 1 & - \\
\hline 20 & 810 & 290 & 5 & 2 & - \\
\hline 21 & 710 & 240 & 3 & 1 & - \\
\hline 22 & 760 & 270 & 5 & 1 & Ileus \\
\hline 23 & 650 & 230 & 4 & 1 & - \\
\hline
\end{tabular}

Abbreviation: SIADH, syndrome of inappropriate antidiuretic hormone.

stay duration were lower than in other studies, and we experienced no major complications.

Surgeons should apply multiple planes correction because of complex 3-dimensional deformity in severe and rigid scoliosis. Decompensation in the coronal and sagittal planes leads to cosmetic complaints, interference with activities of daily living, fatigue, pain, gait problems, neurologic deficits, and cardiopulmonary dysfunction.

The most important part of each procedure in severe and rigid scoliosis is increasing spine flexibility. Choosing a surgical approach for AIS is still controversial. ${ }^{14}$ Surgeon's training status and experience, patient's comorbidity, and type and severity of curves are key factors in deciding which procedure to perform. Some authors have advocated that combined anterior-posterior instrumentation is safe, effective, and leads to good 3dimensional curve correction in severe and rigid idiopathic patients. ${ }^{15}$ There are, however, disadvantages of combined anterior release, including the learning curve for the surgeon, cardiopulmonary compromise, adjacent-organ injuries, increased hospital stay and cost, halo traction complications before posterior procedures, and having the anesthesia risks of 2 major operations. ${ }^{14,16}$ The main problem of the combined anterior and posterior procedure is the risk of pulmonary complica- tions. $^{6,17,18}$ Some studies have used preoperative traction or traction between 2 stages of surgery as a part of correction. ${ }^{19-21}$ However, complications such as neurologic deficit, pin loosening, pin tract infection, brain abscess, and cranial nerve palsies, can occur during traction period. Other authors reported acceptable results with the posterior-only approach in both moderate and severe curves without anterior approach disadvantages. ${ }^{6}$ Chang $^{22}$ used posterior pedicle screws-only instrumentation in 26 cases with thoracic scoliosis between $75^{\circ}$ and $135^{\circ}$ with $67 \%$ correction. Kuklo et $\mathrm{al}^{23}$ used a posterior-only approach in 20 patients (17.6 screws per case) to correct idiopathic scoliosis over $90^{\circ}$, and $68 \%$ correction was achieved. These 2 studies did not explain the osteotomy.

Pedicle screws, with a 3-column purchase, provide the spine surgeon with an enhanced 3dimensional deformity correction. ${ }^{8,9,24}$ Belmont et $\mathrm{al}^{25}$ reported a thoracic pedicle screw placement acceptability rate of $98 \%$ in patients with adolescent idiopathic scoliosis when performed by an experienced surgeon. Suk et $\mathrm{al}^{26}$ reported rates of $1.5 \%$ and $0.8 \%$ for screw malposition and screw-related neurologic complications. Crostelli et $\mathrm{al}^{27}$ reported that greater correction can be achieved by pedicle screw instrumentation compared with hybrid instrumentation in severe rigid scoliosis with a posterior-only approach. Neurologic and visceral complications were rarely reported in thoracic pedicle screws. We performed free hand procedure without navigational aids, and we experienced no neurologic impairment in our patients.

Suk et $\mathrm{al}^{28}$ in their series of 35 severe scoliosis patients treated by posterior segmental pedicle screw fixation alone without anterior release, showed a correction of $66 \%$ (the average preoperative scoliosis of $79^{\circ}$ was corrected to $28^{\circ}$ ) and avoided complications related to anterior surgery. The radiographic results were comparable to those of other studies using anterior release combined with posterior instrumentation without significant loss of curve correction, even in severe deformity. Dobbs et $\mathrm{al}^{29}$ reported no statistically significant differences between the groups for a large-curve AIS $>90^{\circ}$ treated with posterior spinal fusion and with a combined anterior-posterior spinal fusion with same correction rate of $44 \%$. Shi et $a^{30}$ also revealed there was no statistically significant difference between sever rigid scoliosis patients treated with the posterior only approach with an all 
pedicle screw construct (59\% correction) and combined anterior-posterior spinal fusion $(60 \%$ correction).

In recent years, posterior osteotomy and posterior VCR (PVCR) have gained popularity in the treatment of severe rigid scoliosis. Some authors offer PVCR as the first choice for treating severe, rigid kyphoscoliosis and angular kyphosis ${ }^{31}$; however, the reported prevalence of complications ranges from $34.3 \%$ to $64.3 \%$. Suk et $\mathrm{al}^{11}$ reported a series of 16 patients who underwent a posterioronly VCR, with the mean preoperative scoliosis curve of $109^{\circ}$ and correction rate of $59 \%$. However, complications were seen in 4 patients, including complete permanent paralysis in 1 patient. Saifi et $\mathrm{al}^{32}$ reported $50 \%$ to $70 \%$ correction in severe rigid coronal or sagittal malalignment after vertebral column resection, but the technique was associated with significant morbidity. Lenke et $\mathrm{al}^{33}$ reported on PVCR in a series of 35 patients for severe pediatric spinal deformity, with an average preoperative scoliosis of $115^{\circ}\left(79^{\circ}-150^{\circ}\right)$ corrected to $61^{\circ}(51 \%)$. A single-level osteotomy will not affect the flexibility of the spinal segment above and below the osteotomy and cannot achieve 3-dimensional correction of spinal deformity. In a retrospective study, Zhang et $\mathrm{al}^{34}$ compare the efficacy and safety of posterior multiple-level asymmetrical Ponte osteotomies and posterior vertebral column resection for severe and rigid adult idiopathic scoliosis, and they suggested that multiple asymmetrical Ponte osteotomy is a safe, easy-tooperate, and effective technique that can gain correction outcomes similar to those of VCR, offering the advantages of reduced complications, operation time, and blood loss. Some authors ${ }^{29}$ have performed apical Smith Peterson osteotomy for thoracic scoliosis with more than $100^{\circ}$. The technique we used in our study was multiple asymmetric Ponte osteotomy to correct both sagittal and coronal plan deformity. The final correction rate of our study revealed $64.2 \%$, which was comparable with those in previous studies.

This study has several drawbacks, mainly arising from its retrospective nature. There was a limited number of patients in this study, making statistical analysis difficult. In addition, the absence of a control group and the lack of preoperative SRS-30 scores pose a difficulty in interpreting and comparing the clinical outcomes.

\section{CONCLUSION}

According to the results of the present study, we found that a posterior-only procedure in patients with severe and rigid adolescent idiopathic scoliosis could provide deformity correction, coronal and sagittal balance, and complications comparable with other procedures. This technique can eliminate the need for the anterior release, with the associated complications related to the anterior surgery, in the treatment of severe rigid scoliosis.

\section{REFERENCES}

1. Hoashi JS, Cahill PJ, Bennett JT, Samdani AF. Adolescent scoliosis classification and treatment. Neurosurg Clin N Am. 2013;24(2):173-183.

2. Suk SI, Chung ER, Kim JH, Kim SS, Lee JS, Choi WK. Posterior vertebral column resection for severe rigid scoliosis. Spine. 2005;30(14):1682-1687.

3. Shen J, Qiu G, Wang Y, Zhang Z, Zhao Y. Comparison of 1-stage versus 2-stage anterior and posterior spinal fusion for severe and rigid idiopathic scoliosis-a randomized prospective study. Spine. 2006;31(22):2525-2528.

4. Kandwal P, Vijayaraghavan GP, Nagaraja UB, Jayaswal A. Severe rigid scoliosis: review of management strategies and role of spinal osteotomies. Asian Spine J. 2017;11(3):494-503.

5. Nemani VM, Kim HJ, Bjerke-Kroll BT, et al. Preoperative halo-gravity traction for severe spinal deformities at an SRS-GOP site in West Africa: protocols, complications, and results. Spine. 2015;40(3):153-161.

6. Kim YJ, Lenke LG, Bridwell KH, Kim KL, Steger-May K. Pulmonary function in adolescent idiopathic scoliosis relative to the surgical procedure. J Bone Joint Surg. 2005;87(7):1534-1541.

7. Newton PO, Wenger DR, Mubarak SJ, Meyer RS. Anterior release and fusion in pediatric spinal deformity: a comparison of early outcome and cost of thoracoscopic and open thoracotomy approaches. Spine. 1997;22(12):1398-1406.

8. Suk SI, Kim WJ, Kim JH, Lee SM. Restoration of thoracic kyphosis in the hypokyphotic spine: a comparison between multiple-hook and segmental pedicle screw fixation in adolescent idiopathic scoliosis. J Spinal Disord. 1999;12(6):489495.

9. Suk SI, Lee CK, Kim WJ, Chung YJ, Park YB. Segmental pedicle screw fixation in the treatment of thoracic idiopathic scoliosis. Spine. 1995;20(12):1399-1405.

10. Bradford DS, Tribus CB. Vertebral column resection for the treatment of rigid coronal decompensation. Spine. 1997;22(14):1590-1599.

11. Suk SI, Kim JH, Kim WJ, Lee SM, Chung ER, Nah KH. Posterior vertebral column resection for severe spinal deformities. Spine. 2002;27(21):2374-2382.

12. Lenke LG, Betz RR, Harms J, et al. Adolescent idiopathic scoliosis: a new classification to determine extent of spinal arthrodesis. J Bone Joint Surg. 2001;83(8):1169-1181.

13. Ortmann E, Besser MW, Klein AA. Antifibrinolytic agents in current anaesthetic practice. $\mathrm{Br} J$ Anaesth. 2013;111(4):549-563 
14. Chen Z, Rong L. Comparison of combined anteriorposterior approach versus posterior-only approach in treating adolescent idiopathic scoliosis: a meta-analysis. Eur Spine J. 2016;25(2):363-371.

15. Bullmann V, Halm HF, Schulte T, Lerner T, Weber TP, Liljenqvist UR. Combined anterior and posterior instrumentation in severe and rigid idiopathic scoliosis. Eur Spine J. 2006;15(4):440-448.

16. Zhang HQ, Wang YX, Guo CF, et al. Posterior-only surgery with strong halo-femoral traction for the treatment of adolescent idiopathic scoliotic curves more than 100 degrees. Int Orthop. 2011;35(7):1037-1042.

17. Vedantam R, Lenke LG, Bridwell KH, Haas J, Linville DA. A prospective evaluation of pulmonary function in patients with adolescent idiopathic scoliosis relative to the surgical approach used for spinal arthrodesis. Spine. 2000;25(1):82-90.

18. Lenke LG, Bridwell KH, Blanke K, Baldus C. Analysis of pulmonary function and chest cage dimension changes after thoracoplasty in idiopathic scoliosis. Spine. 1995;20(12):13431350 .

19. Qiu Y, Liu Z, Zhu F, et al. Comparison of effectiveness of Halo-femoral traction after anterior spinal release in severe idiopathic and congenital scoliosis: a retrospective study. $J$ Orthop Surg Res. 2007;2:23.

20. Rinella A, Lenke L, Whitaker C, et al. Perioperative halo-gravity traction in the treatment of severe scoliosis and kyphosis. Spine. 2005;30(4):475-482.

21. Hamzaoglu A, Ozturk C, Aydogan M, Tezer M, Aksu N, Bruno MB. Posterior only pedicle screw instrumentation with intraoperative halo-femoral traction in the surgical treatment of severe scoliosis ( $>100$ degrees). Spine. 2008;33(9):979-983.

22. Chang KW. Cantilever bending technique for treatment of large and rigid scoliosis. Spine. 2003;28(21):2452-2458.

23. Kuklo TR, Lenke LG, O'Brien MF, Lehman RA Jr, Polly DW Jr, Schroeder TM. Accuracy and efficacy of thoracic pedicle screws in curves more than 90 degrees. Spine. 2005;30(2):222-226.

24. Liljenqvist UR, Halm HF, Link TM. Pedicle screw instrumentation of the thoracic spine in idiopathic scoliosis. Spine. 1997;22(19):2239-2245.

25. Belmont PJ Jr, Klemme WR, Dhawan A, Polly DW Jr. In vivo accuracy of thoracic pedicle screws. Spine. 2001;26(21):2340-2346.

26. Suk SI, Kim WJ, Lee SM, Kim JH, Chung ER. Thoracic pedicle screw fixation in spinal deformities: are they really safe? Spine. 2001;26(18):2049-2057.

27. Crostelli M, Mazza O, Mariani M, Mascello D. Treatment of severe scoliosis with posterior-only approach arthrodesis and all-pedicle screw instrumentation. Eur Spine J. 2013;22(suppl 6):S808-S814.
28. Suk SI, Kim JH, Cho KJ, Kim SS, Lee JJ, Han YT. Is anterior release necessary in severe scoliosis treated by posterior segmental pedicle screw fixation? Eur Spine J. 2007;16(9):13591365 .

29. Dobbs MB, Lenke LG, Kim YJ, Luhmann SJ, Bridwell KH. Anterior/posterior spinal instrumentation versus posterior instrumentation alone for the treatment of adolescent idiopathic scoliotic curves more than 90 degrees. Spine. 2006;31(20):2386-2391.

30. Shi Z, Chen J, Wang C, et al. Comparison of thoracoscopic anterior release combined with posterior spinal fusion versus posterior-only approach with an all-pedicle screw construct in the treatment of rigid thoracic adolescent idiopathic scoliosis. J Spinal Disord Tech. 2015;28(8):E454 E459.

31. Xie JM, Chen ZQ, Shen JX, et al. Expert consensus for PVCR in severe, rigid and angular spinal deformity treatment: the Kunming consensus. J Orthop Surg (Hong Kong). 2017;25(2):2309499017713939.

32. Saifi C, Laratta JL, Petridis P, Shillingford JN, Lehman RA, Lenke LG. Vertebral column resection for rigid spinal deformity. Global Spine J. 2017;7(3):280-290.

33. Lenke LG, O'Leary PT, Bridwell KH, et al. Posterior vertebral column resection for severe pediatric deformity: minimum two-year follow-up of thirty-five consecutive patients. Spine. 2009;34:2213-2221.

34. Zhang Y, Tao L, Hai Y, et al. One-stage posterior multiple-level asymmetrical Ponte osteotomies versus singlelevel posterior vertebral column resection for severe and rigid adult idiopathic scoliosis: a minimum 2-year follow-up comparative study. Spine. 2019;44(20):E1196-E1205.

Disclosures and COI: There were no conflicts of interest. This work was supported by Tehran University of Medical Sciences.

Corresponding Author: Mohsen Rostami, $\mathrm{MD}, \mathrm{PhD}$, Sports Medicine Research Center, Neuroscience Institute, Tehran University of Medical Sciences, No. 7, Al-e Ahmad Highway, Tehran, Iran. Tel.: (+98) 21 88630227-8; E-mail: rostami. moh@gmail.com

Published 30 April 2020

This manuscript is generously published free of charge by ISASS, the International Society for the Advancement of Spine Surgery. Copyright $\odot 2020$ ISASS. To see more or order reprints or permissions, see http://ijssurgery.com. 